\title{
A interdisciplinaridade como um movimento articulador no processo ensino-aprendizagem
}

\author{
Juares da Silva Thiesen \\ Universidade do Estado de Santa Catarina, Centro de Educação \\ Centro Universitário de São José, Departamento de Educação
}

\section{Introdução}

A discussão sobre a temática da interdisciplinaridade tem sido tratada por dois grandes enfoques: o epistemológico e o pedagógico, ambos abarcando conceitos diversos e muitas vezes complementares. No campo da epistemologia, toma-se como categorias para seu estudo o conhecimento em seus aspectos de produção, reconstrução e socialização; a ciência e seus paradigmas; e o método como mediação entre o sujeito e a realidade. Pelo enfoque pedagógico, discutem-se fundamentalmente questões de natureza curricular, de ensino e de aprendizagem escolar.

O movimento histórico que vem marcando a presença do enfoque interdisciplinar na educação constitui um dos pressupostos diretamente relacionados a um contexto mais amplo e também muito complexo de mudanças que abrange não só a área da educação mas também outros setores da vida social como a economia, a política e a tecnologia. Trata-se de uma grande mudança paradigmática que está em pleno curso.

Maria Cândida Moraes (2002), na obra $O \mathrm{pa}$ radigma educacional emergente, ressalta que, se a realidade é complexa, ela requer um pensamento abrangente, multidimensional, capaz de compreender a complexidade do real e construir um conhecimento que leve em consideração essa mesma amplitude.

A necessidade da interdisciplinaridade na produção e na socialização do conhecimento no campo educativo vem sendo discutida por vários autores, principalmente por aqueles que pesquisam as teorias curriculares e as epistemologias pedagógicas. De modo geral, a literatura sobre esse tema mostra que existe pelo menos uma posição consensual quanto ao sentido e à finalidade da interdisciplinaridade: ela busca responder à necessidade de superação da visão fragmentada nos processos de produção e socialização do conhecimento. Trata-se de um movimento que caminha para novas formas de organização do conhecimento ou para um novo sistema de sua produção, difusão e transferência, como propõem Michael Gibbons e outros (1997).

$\mathrm{Na}$ análise de Frigotto (1995, p. 26), a interdisciplinaridade impõe-se pela própria forma de o "homem produzir-se enquanto ser social e enquanto sujeito e objeto do conhecimento social". Ela funda-se 
no caráter dialético da realidade social, pautada pelo princípio dos conflitos e das contradições, movimentos complexos pelos quais a realidade pode ser percebida como una e diversa ao mesmo tempo, algo que nos impõe delimitar os objetos de estudo demarcando seus campos sem, contudo, fragmentá-los. Significa que, embora delimitado o problema a ser estudado, não podemos abandonar as múltiplas determinações e mediações históricas que o constituem.

Dadas a natureza e a especificidade deste artigo, tomar-se-á como principal ponto de reflexão o papel da interdisciplinaridade no processo de ensinar e de aprender na escolarização formal, buscando-se articular as abordagens pedagógica e epistemológica, com seus avanços, limitações, conflitos e consensos.

Edgar Morin (2005), um dos teóricos desse movimento, entende que só o pensamento complexo sobre uma realidade também complexa pode fazer avançar a reforma do pensamento na direção da contextualização, da articulação e da interdisciplinarização do conhecimento produzido pela humanidade. Para ele:

\footnotetext{
[...] a reforma necessária do pensamento é aquela que gera um pensamento do contexto e do complexo. O pensamento contextual busca sempre a relação de inseparabilidade e as inter-retroações entre qualquer fenômeno e seu contexto, e deste com o contexto planetário. O complexo requer um pensamento que capte relações, inter-relações, implicações mútuas, fenômenos multidimensionais, realidades que são simultaneamente solidárias e conflitivas (como a própria democracia, que é o sistema que se nutre de antagonismos e que, simultaneamente, os regula), que respeite a diversidade, ao mesmo tempo que a unidade, um pensamento organizador que conceba a relação recíproca entre todas as partes. (p. 23)
}

Nesse sentido, a interdisciplinaridade será articuladora do processo de ensino e de aprendizagem na medida em que se produzir como atitude (Fazenda, 1979), como modo de pensar (Morin, 2005), como pressuposto na organização curricular (Japiassu, 1976), como fundamento para as opções metodológicas do ensinar (Gadotti, 2004), ou ainda como elemento orientador na formação dos profissionais da educação.

\section{Origem e conceitos de interdisciplinaridade}

A interdisciplinaridade, como um enfoque teórico-metodológico ou gnosiológico, como a denomina Gadotti (2004), surge na segunda metade do século passado, em resposta a uma necessidade verificada principalmente nos campos das ciências humanas e da educação: superar a fragmentação e o caráter de especialização do conhecimento, causados por uma epistemologia de tendência positivista em cujas raízes estão o empirismo, o naturalismo e o mecanicismo científico do início da modernidade.

Sobretudo pela influência dos trabalhos de grandes pensadores modernos como Galileu, Bacon, Descartes, Newton, Darwin e outros, as ciências foram sendo divididas e, por isso, especializando-se. Organizadas, de modo geral, sob a influência das correntes de pensamento naturalista e mecanicista, buscavam, já a partir da Renascença, construir uma concepção mais científica de mundo. A interdisciplinaridade, como um movimento contemporâneo que emerge na perspectiva da dialogicidade e da integração das ciências e do conhecimento, vem buscando romper com o caráter de hiperespecialização e com a fragmentação dos saberes.

Para Goldman (1979, p. 3-25), um olhar interdisciplinar sobre a realidade permite que entendamos melhor a relação entre seu todo e as partes que a constituem. Para ele, apenas o modo dialético de pensar, fundado na historicidade, poderia favorecer maior integração entre as ciências. Nesse sentido, o materialismo histórico e dialético resolveu em parte o problema da fragmentação do conhecimento quando colocou a historicidade e as leis do movimento dialético da realidade como fundamentos para todas as ciências. Desde então, o conceito de interdisciplinaridade vem sendo discutido nos diferentes âmbitos científicos e muito fortemente na educação. Sem dúvida, tanto as formulações filosóficas do materialismo histórico e dialético quanto as proposições pedagógicas das 
teorias críticas trouxeram contribuições importantes para esse novo enfoque epistemológico.

De fato, é no campo das ciências humanas e sociais que a interdisciplinaridade aparece com maior força. A preocupação com uma visão mais totalizadora da realidade cognoscível e com a conseqüente dialogicidade das ciências foi objeto de estudo primeiramente na filosofia, posteriormente nas ciências sociais e mais recentemente na epistemologia pedagógica. Trabalhos como o de Kapp (1961), Piaget (1973), Vygotsky (1986), Durand (1991), Snow (1959) e Gusdorf (1967) são alguns exemplos desse movimento.

Goldman (1979) destaca que, inicialmente, a interdisciplinaridade aparece como preocupação humanista, além da preocupação com as ciências. Desde então, parece que todas as correntes de pensamento se ocuparam com a questão da interdisciplinaridade: a teologia fenomenológica encontrou nesse conceito uma chave para o diálogo entre Igreja e mundo; o existencialismo buscou dar às ciências uma cara mais humana; a epistemologia buscou desvendar o processo de construção do conhecimento e garantir maior integração entre as ciências, e o materialismo histórico e dialético buscou, no método indutivo-dedutivoindutivo, uma via para integrar parte e todo.

Mais voltado à pedagogia, Georges Gusdorf lançou na década de 1960 um projeto interdisciplinar para as ciências humanas apresentado à Organização das Nações Unidas para a Educação, a Ciência e a Cultura (UNESCO). Sua obra La parole (1953) é considerada muito importante para entender a interdisciplinaridade. O projeto de interdisciplinaridade nas ciências passou de uma fase filosófica (humanista), de definição e explicitação terminológica, na década de 1970, para uma segunda fase (mais científica), de discussão do seu lugar nas ciências humanas e na educação a partir da década de 1980.

Gadotti (1993) ressalta que atualmente, no plano teórico, se busca fundar a interdisciplinaridade na ética e na antropologia, ao mesmo tempo em que, no plano prático, surgem projetos que reivindicam uma visão interdisciplinar, sobretudo no campo do ensino e do currículo. No Brasil, o conceito de interdisci- plinaridade chegou pelo estudo da obra de Georges Gusdorf e posteriormente da de Piaget. O primeiro autor influenciou o pensamento de Hilton Japiassu no campo da epistemologia e o de Ivani Fazenda no campo da educação.

Quanto à definição de conceitos, ou de um conceito, para interdisciplinaridade, tudo parece estar ainda em construção. Qualquer demanda por uma definição unívoca e definitiva deve ser a princípio rejeitada, por tratar-se de proposta que inevitavelmente está sendo construída a partir das culturas disciplinares existentes e porque encontrar o limite objetivo de sua abrangência conceitual significa concebê-la numa óptica também disciplinar. Ou, como afirma Leis (2005, p. 7), "a tarefa de procurar definições finais para a interdisciplinaridade não seria algo propriamente interdisciplinar, senão disciplinar".

Para esse autor (2005), na medida em que não existe uma definição única possível para esse conceito, senão muitas, tantas quantas sejam as experiências interdisciplinares em curso no campo do conhecimento, entendemos que se deva evitar procurar definições abstratas de interdisciplinaridade. Os conhecimentos disciplinares são paradigmáticos (no sentido de Kuhn, 1989), mas não são assim os interdisciplinares. Portanto, a história da interdisciplinaridade confunde-se com a dinâmica viva do conhecimento. $\mathrm{O}$ mesmo não pode ser dito da história das disciplinas, que congelam de forma paradigmática o conhecimento alcançado em determinado momento histórico, defendendo-se de qualquer abordagem alternativa numa guerra de trincheiras.

O que se pode afirmar no campo conceitual é que a interdisciplinaridade será sempre uma reação alternativa à abordagem disciplinar normalizadora (seja no ensino ou na pesquisa) dos diversos objetos de estudo. Independente da definição que cada autor assuma, a interdisciplinaridade está sempre situada no campo onde se pensa a possibilidade de superar a fragmentação das ciências e dos conhecimentos produzidos por elas e onde simultaneamente se exprime a resistência sobre um saber parcelado.

Para Japiassu (1976), a interdisciplinaridade 
caracteriza-se pela intensidade das trocas entre os especialistas e pelo grau de integração real das disciplinas no interior de um mesmo projeto. A interdisciplinaridade visa à recuperação da unidade humana pela passagem de uma subjetividade para uma intersubjetividade e, assim sendo, recupera a idéia primeira de cultura (formação do homem total), o papel da escola (formação do homem inserido em sua realidade) e o papel do homem (agente das mudanças do mundo). Portanto, mais do que identificar um conceito para interdisciplinaridade, o que os autores buscam é encontrar seu sentido epistemológico, seu papel e suas implicações sobre o processo do conhecer.

Partindo do pressuposto apresentado por Japiassu (1976), de que a interdisciplinaridade se caracteriza pela intensidade das trocas entre os especialistas e pelo grau de integração real das disciplinas no interior de um mesmo projeto de pesquisa, exige-se que as disciplinas, ${ }^{1}$ em seu processo constante e desejável de interpenetração, se fecundem cada vez mais reciprocamente. Para tanto, é imprescindível a complementaridade dos métodos, dos conceitos, das estruturas e dos axiomas sobre os quais se fundam as diversas práticas pedagógicas das disciplinas científicas.

Japiassu (1976) destaca ainda:

[...] do ponto de vista integrador, a interdisciplinaridade requer equilíbrio entre amplitude, profundidade e síntese. A amplitude assegura uma larga base de conhecimento e informação. A profundidade assegura o requisito disciplinar e/ou conhecimento e informação interdisciplinar para a tarefa a ser executada. A síntese assegura o processo integrador. (p. 65-66)

As abordagens teóricas apresentadas pelos vários autores vão deixando claro que o pensamento e as práticas interdisciplinares, tanto nas ciências em geral quanto na educação, não põem em xeque a dimensão

${ }^{1}$ Entende-se a disciplina como um espaço de organização, sistematização e socialização dos conhecimentos parciais produzidos no âmbito de uma ciência para fins de ensino e pesquisa. disciplinar do conhecimento em suas etapas de investigação, produção e socialização. O que se propõe é uma profunda revisão de pensamento, que deve caminhar no sentido da intensificação do diálogo, das trocas, da integração conceitual e metodológica nos diferentes campos do saber.

Nas palavras de Japiassu:

Podemos dizer que nos reconhecemos diante de um empreendimento interdisciplinar todas as vezes em que ele conseguir incorporar os resultados de várias especialidades, que tomar de empréstimo a outras disciplinas certos instrumentos e técnicas metodológicos, fazendo uso dos esquemas conceituais e das análises que se encontram nos diversos ramos do saber, a fim de fazê-los integrarem e convergirem, depois de terem sido comparados e julgados. Donde podermos dizer que o papel específico da atividade interdisciplinar consiste, primordialmente, em lançar uma ponte para ligar as fronteiras que haviam sido estabelecidas anteriormente entre as disciplinas com o objetivo preciso de assegurar a cada uma seu caráter propriamente positivo, segundo modos particulares e com resultados específicos. (1976, p. 75)

\section{Epistemologia, ciência e interdisciplinaridade}

Para Morin (2005, p. 44), certas concepções científicas mantêm sua vitalidade porque se recusam ao claustro disciplinar. A especialização do conhecimento científico é uma tendência que nada tem de acidental. Ao contrário, é condição de possibilidade do próprio progresso do conhecimento, expressão das exigências analíticas que caracterizam o programa de desenvolvimento da ciência que vem dos gregos e que foi reforçado no século XVII, principalmente com Galileu e Descartes. Para lá das diferenças que os distinguem, eles comungam de uma mesma perspectiva metódica: pelo método indutivo, dividir o objeto de estudo para estudar finamente seus elementos constituintes e, depois, recompor o todo a partir daí.

Ainda que os membros do Círculo de Viena tenham buscado elementos científicos para justificar 
a constituição de uma "ciência unificada" e tenham, por via do método indutivo, buscado encontrar a verdade concreta ou uma concepção científica de mundo, o positivismo, desde sua fase comtiana, seguiu contribuindo para uma espécie de fragmentação ou especialização dos saberes, com o alargamento das fronteiras entre as disciplinas e, por conseqüência, com a divulgação de uma concepção positiva de mundo, de natureza e de sociedade. A interdisciplinaridade, como reação a essa concepção, vem com a proposta de romper com a fragmentação das disciplinas, das ciências, enfim, do conhecimento.

A superação dos limites que encontramos na produção do conhecimento e nos processos pedagógicos e de socialização exige que sejam rompidas as relações sociais que estão na base desses limites. No plano epistemológico (das relações sujeito/objeto), mediadas pela teoria científica que dá sustentação lógica a essa relação, Frigotto (1995) diz que a interdisciplinaridade precisa, acima de tudo, de uma discussão de paradigma, situando o problema no plano teórico-metodológico. Precisamos, segundo ele, perceber que a interdisciplinaridade não se efetiva se não transcendermos a visão fragmentada e o plano fenomênico, ambos marcados pelo paradigma empirista e positivista.

Frigotto (1995) mostra que, no plano ontológico (plano material histórico-cultural), o desafio que enfrentamos constitui antes um problema ético-político, econômico e cultural. Para ele, as relações sociais na estruturação da sociedade moderna limitam e impedem o devir humano, na medida em que a exclusão e a alienação fazem parte da lógica da sociedade capitalista.

Parece evidente que a responsabilidade pela legitimação social e científica da especialização e da fragmentação do conhecimento recai basicamente sobre o positivismo, a partir do qual se fortaleceram o cientificismo, o pragmatismo e o empirismo. Japiassu faz esta constatação quando destaca:

A nosso ver, foi uma filosofia das ciências, mais precisamente o positivismo, que constituiu o grande veículo e o suporte fundamental dos obstáculos epistemológicos ao conhecimento interdisciplinar, porque nenhuma outra filosofia estruturou tanto quanto ela as relações dos cientistas com suas práticas. E sabemos o quanto esta estruturação foi marcada pela compartimentação das disciplinas, em nome de uma exigência metodológica de demarcação de cada objeto particular, constituindo a propriedade privada desta ou daquela disciplina. (1976, p. 96-97)

Nessa mesma direção, Olga Pombo (2004) ressalta que a especialização é uma tendência da ciência moderna, exponencial a partir do século XIX. Segundo ela:

[...] a ciência moderna se constitui pela adopção da metodologia analítica proposta por Galileu e Descartes. Isto é, se constituiu justamente no momento em que adoptou uma metodologia que lhe permitia "esquartejar" cada totalidade, cindir o todo em pequenas partes por intermédio de uma análise cada vez mais fina. Ao dividir o todo nas suas partes constitutivas, ao subdividir cada uma dessas partes até aos seus mais ínfimos elementos, a ciência parte do princípio de que, mais tarde, poderá recompor o todo, reconstituir a totalidade. A idéia subjacente é a de que o todo é igual à soma das partes. (p. 5-6)

Todavia, o desenvolvimento das diferentes áreas científicas, sobretudo a partir da segunda metade do século XX, vem dependendo muito mais da relação recíproca e da fertilização heurística de umas disciplinas por outras, da transferência de conceitos, de problemas e métodos. Há uma espécie de inteligência interdisciplinar na ciência contemporânea.

Ou, como diz Pombo (2004, p. 10):

Trata-se de reconhecer que determinadas investigações reclamam a sua própria abertura para conhecimentos que pertencem, tradicionalmente, ao domínio de outras disciplinas e que só essa abertura permite aceder a camadas mais profundas da realidade que se quer estudar. Estamos perante transformações epistemológicas muito profundas. É como se o próprio mundo resistisse ao seu retalhamento disciplinar. A ciência começa a aparecer como um processo que exige também um olhar transversal. 
Para ilustrar essa afirmação, a autora exemplifica com casos bem concretos vivenciados no campo da ciência contemporânea, como o da bioquímica, o da biofísica, o da engenharia e o da genética; estas duas últimas áreas - a engenharia e a genética - cuja mistura parecia impensável há 60 ou 70 anos. Algumas delas têm sido designadas como ciências de fronteira - novas disciplinas que nascem nas fronteiras entre duas disciplinas tradicionais -, outras como interdisciplinas - aquelas que nascem na confluência entre ciências puras e ciências aplicadas. É nessa nova situação epistemológica que as novas disciplinas ou ciências vêm sendo constituídas.

Nessa mesma reflexão, Olga Pombo (2004) faz outra observação muito importante, que mostra bem o esforço da ciência para superar o caráter disciplinar que marcou boa parte da modernidade. Segundo ela, já é possível identificar a existência de interciências, que seriam conjuntos disciplinares nos quais não há já uma ciência que nasça nas fronteiras de duas disciplinas fundamentais (ciências de fronteira) ou que resulte do cruzamento de ciências puras e aplicadas (interdisciplinas), mas que se ligam, de forma descentrada, assimétrica, irregular, capaz de resolver um problema preciso. Bons exemplos, segundo ela, são as ciências cognitivas e as ciências da computação. São conjuntos de disciplinas que se encontram de forma irregular e descentrada para colaborar na discussão de um problema comum. A juventude urbana, o envelhecimento, a violência, o clima ou a manipulação genética, por exemplo, são novidades epistemológicas que só um enfoque interdisciplinar pode procurar dar resposta.

\section{Implicações da interdisciplinaridade no processo de ensino e aprendizagem}

A escola, como lugar legítimo de aprendizagem, produção e reconstrução de conhecimento, cada vez mais precisará acompanhar as transformações da ciência contemporânea, adotar e simultaneamente apoiar as exigências interdisciplinares que hoje participam da construção de novos conhecimentos. A escola precisará acompanhar o ritmo das mudanças que se operam em todos os segmentos que compõem a sociedade. O mundo está cada vez mais interconectado, interdisciplinarizado e complexo.

Ainda é incipiente, no contexto educacional, o desenvolvimento de experiências verdadeiramente interdisciplinares, embora haja um esforço institucional nessa direção. Não é difícil identificar as razões dessas limitações; basta que verifiquemos o modelo disciplinar e desconectado de formação presente nas universidades, lembrar da forma fragmentária como estão estruturados os currículos escolares, a lógica funcional e racionalista que o poder público e a iniciativa privada utilizam para organizar seus quadros de pessoal técnico e docente, a resistência dos educadores quando questionados sobre os limites, a importância e a relevância de sua disciplina e, finalmente, as exigências de alguns setores da sociedade que insistem num saber cada vez mais utilitário.

Embora a temática da interdisciplinaridade esteja em debate tanto nas agências formadoras quanto nas escolas, sobretudo nas discussões sobre projeto político-pedagógico, os desafios para a superação do referencial dicotomizador e parcelado na reconstrução e socialização do conhecimento que orienta a prática dos educadores ainda são enormes.

Para Luck (2001), o estabelecimento de um trabalho de sentido interdisciplinar provoca, como toda ação a que não se está habituado, sobrecarga de trabalho, certo medo de errar, de perder privilégios e direitos estabelecidos. A orientação para o enfoque interdisciplinar na prática pedagógica implica romper hábitos e acomodações, implica buscar algo novo e desconhecido. É certamente um grande desafio (p. 68).

Não obstantes as limitações da prática, a interdisciplinaridade está sendo entendida como uma condição fundamental do ensino e da pesquisa na sociedade contemporânea. A ação interdisciplinar é contrária a qualquer homogeneização e/ou enquadramento conceitual. Faz-se necessário o desmantelamento das fronteiras artificiais do conhecimento. Um processo educativo desenvolvido na perspectiva interdisciplinar possibilita o aprofundamento 
da compreensão da relação entre teoria e prática, contribui para uma formação mais crítica, criativa e responsável e coloca escola e educadores diante de novos desafios tanto no plano ontológico quanto no plano epistemológico.

Por certo as aprendizagens mais necessárias para estudantes e educadores, neste tempo de complexidade e inteligência interdisciplinar, sejam as de integrar o que foi dicotomizado, religar o que foi desconectado, problematizar o que foi dogmatizado e questionar o que foi imposto como verdade absoluta. Essas são possivelmente as maiores tarefas da escola nesse movimento.

Na sala de aula, ou em qualquer outro ambiente de aprendizagem, são inúmeras as relações que intervêm no processo de construção e organização do conhecimento. As múltiplas relações entre professores, alunos e objetos de estudo constroem o contexto de trabalho dentro do qual as relações de sentido são construídas. Nesse complexo trabalho, o enfoque interdisciplinar aproxima o sujeito de sua realidade mais ampla, auxilia os aprendizes na compreensão das complexas redes conceituais, possibilita maior significado e sentido aos conteúdos da aprendizagem, permitindo uma formação mais consistente e responsável.

A nova espacialidade do processo de aprender e ensinar e a desterritorialidade das relações que engendram o mundo atual indicam claramente o novo caminho da educação diante das demandas sociais, sobretudo as mediadas pela tecnologia. Nessa direção, emergem novas formas de ensinar e aprender que ampliam significativamente as possibilidades de inclusão, alterando profundamente os modelos cristalizados pela escola tradicional. Num mundo com relações e dinâmicas tão diferentes, a educação e as formas de ensinar e de aprender não devem ser mais as mesmas. Um processo de ensino baseado na transmissão linear e parcelada da informação livresca certamente não será suficiente.

Para Ivani Fazenda (1979, p. 48-49), a introdução da interdisciplinaridade implica simultaneamente uma transformação profunda da pedagogia, um novo tipo de formação de professores e um novo jeito de ensinar:
Passa-se de uma relação pedagógica baseada na transmissão do saber de uma disciplina ou matéria, que se estabelece segundo um modelo hierárquico linear, a uma relação pedagógica dialógica na qual a posição de um é a posição de todos. Nesses termos, o professor passa a ser o atuante, o crítico, o animador por excelência.

Para Gadotti (2004), a interdisciplinaridade visa garantir a construção de um conhecimento globalizante, rompendo com as fronteiras das disciplinas. Para isso, integrar conteúdos não seria suficiente. É preciso, como sustenta Ivani Fazenda (1979), também uma atitude interdisciplinar, condição esta, a nosso ver, manifestada no compromisso profissional do educador, no envolvimento com os projetos de trabalho, na busca constante de aprofundamento teórico e, sobretudo, na postura ética diante das questões e dos problemas que envolvem o conhecimento.

Pedro Demo (2001) também nos ajuda a pensar sobre a importância da interdisciplinaridade no processo de ensino e aprendizagem quando propõe que a pesquisa seja um princípio educativo e científico. Para ele, disseminar informação, conhecimento e patrimônios culturais é tarefa fundamental, mas nunca apenas os transmitimos. Na verdade, reconstruímos. Por isso mesmo, a aprendizagem é sempre um fenômeno reconstrutivo e político, nunca apenas reprodutivo.

Para Paulo Freire (1987), a interdisciplinaridade é o processo metodológico de construção do conhecimento pelo sujeito com base em sua relação com o contexto, com a realidade, com sua cultura. Busca-se a expressão dessa interdisciplinaridade pela caracterização de dois movimentos dialéticos: a problematização da situação, pela qual se desvela a realidade, e a sistematização dos conhecimentos de forma integrada.

De todo modo, o professor precisa tornar-se um profissional com visão integrada da realidade, compreender que um entendimento mais profundo de sua área de formação não é suficiente para dar conta de todo o processo de ensino. Ele precisa apropriar-se também das múltiplas relações conceituais que sua área de formação estabelece com as outras ciências. 
O conhecimento não deixará de ter seu caráter de especialidade, sobretudo quando profundo, sistemático, analítico, meticulosamente reconstruído; todavia, ao educador caberá o papel de reconstruí-lo dialeticamente na relação com seus alunos por meio de métodos e processos verdadeiramente produtivos.

A escola é um ambiente de vida e, ao mesmo tempo, um instrumento de acesso do sujeito à cidadania, à criatividade e à autonomia. Não possui fim em si mesma. Ela deve constituir-se como processo de vivência, e não de preparação para a vida. Por isso, sua organização curricular, pedagógica e didática deve considerar a pluralidade de vozes, de concepções, de experiências, de ritmos, de culturas, de interesses. A escola deve conter, em si, a expressão da convivialidade humana, considerando toda a sua complexidade. A escola deve ser, por sua natureza e função, uma instituição interdisciplinar.

Olga Pombo (2003) afirma que há um alargamento do conceito de ciência e, por isso, a necessidade de reorganização das estruturas da aprendizagem das ciências e, por consequiência, das formas de aprender e de ensinar. Em outras palavras: o alargamento do conceito de ciência é tão profundo que muitas vezes é difícil estabelecer a fronteira entre a ciência e a política, a ciência e a economia, a ciência e a vida das comunidades humanas, a ciência e a arte e assim por diante. Por isso, quanto mais interdisciplinar for o trabalho docente, quanto maiores forem as relações conceituais estabelecidas entre as diferentes ciências, quanto mais problematizantes, estimuladores, desafiantes e dialéticos forem os métodos de ensino, maior será a possibilidade de apreensão do mundo pelos sujeitos que aprendem.

Só haverá interdisciplinaridade no trabalho e na postura do educador se ele for capaz de partilhar o domínio do saber, se tiver a coragem necessária para abandonar o conforto da linguagem estritamente técnica e aventurar-se num domínio que é de todos e de que, portanto, ninguém é proprietário exclusivo. Não se trata de defender que, com a interdisciplinaridade, se alcançaria uma forma de anular o poder que todo saber implica (o que equivaleria a cair na utopia beata do sábio sem poder), mas de acreditar na possibilidade de partilhar o poder que se tem, ou melhor, de desejar partilhá-lo.

A abordagem interdisciplinar, como proposta de revisão do pensamento positivista na educação, está fortemente presente nas atuais correntes, tendências e concepções teóricas que tratam do fenômeno da aprendizagem. Maria Cândida Moraes (2002), ao discutir as implicações do paradigma educacional emergente, destaca a presença desse enfoque no construtivismo piagetiano, na pedagogia libertadora de Freire, na teoria das inteligências múltiplas de Gardner, na abordagem histórico-cultural de Vygotsky, na teoria da complexidade de Morin, nas formulações de Capra, Papert, Prigogine, Bohm, Boaventura Sousa Santos e vários outros.

\section{Considerações finais}

O que apresentamos até agora nos permite afirmar que a interdisciplinaridade, tanto em sua dimensão epistemológica quanto pedagógica, está sustentada por um conjunto de princípios teóricos formulados sobretudo por autores que analisam criticamente o modelo positivista das ciências e buscam resgatar o caráter de totalidade do conhecimento. Abordagens teóricas construídas pela óptica da dialética, da fenomenologia, da hermenêutica e do paradigma sistêmico são formulações que sustentam esse movimento produzindo mudanças profundas no mundo das ciências em geral e da educação em particular.

A interdisciplinaridade, como fenômeno gnosiológico e metodológico, está impulsionando transformações no pensar e no agir humanos em diferentes sentidos. Retoma, aos poucos, o caráter de interdependência e interatividade existente entre as coisas e as idéias, resgata a visão de contexto da realidade, demonstra que vivemos numa grande rede ou teia de interações complexas e recupera a tese de que todos os conceitos e teorias estão conectados entre si. Ajuda a compreender que os indivíduos não aprendem apenas usando a razão, o intelecto, mas também a intuição, as sensações, as emoções e os sentimentos. É um movimento que acredita na criatividade das pessoas, na 
complementaridade dos processos, na inteireza das relações, no diálogo, na problematização, na atitude crítica e reflexiva, enfim, numa visão articuladora que rompe com o pensamento disciplinar, parcelado, hierárquico, fragmentado, dicotomizado e dogmatizado que marcou por muito tempo a concepção cartesiana de mundo.

Portanto, a interdisciplinaridade é um movimento importante de articulação entre o ensinar e o aprender. Compreendida como formulação teórica e assumida enquanto atitude, tem a potencialidade de auxiliar os educadores e as escolas na ressignificação do trabalho pedagógico em termos de currículo, de métodos, de conteúdos, de avaliação e nas formas de organização dos ambientes para a aprendizagem.

\section{Referências bibliográficas}

DEMO, Pedro. Educação \& conhecimento - relação necessária, insuficiente e controversa. Petrópolis: Vozes, 2001.

DURAND, G. Multidisciplinarités et heuristique. In: PORTELLA, E. (Org.). Entre savoirs. L'Interdisciplinarité en acte: enjeux, obstacles, perspectives. Toulouse: Ères /UNESCO, 1991.

ETGES, Norberto Jacob. Produção do conhecimento e interdisciplinaridade. Educação e Realidade, Porto Alegre: Faculdade de Educação da UFRGS, v. 18, n. 2, p. 73-82, jul./dez. 1993.

FAZENDA, Ivani C. Integração e interdisciplinaridade no ensino brasileiro: efetividade ou ideologia. São Paulo: Loyola, 1979.

FREIRE, Paulo. Pedagogia do oprimido. Rio de Janeiro: Paz e Terra, 1987.

FRIGOTTO, Gaudêncio. A interdisciplinaridade como necessidade e como problema nas ciências sociais. In: JANTSCH, Ari Paulo; BIANCHETTI, Lucídio (Orgs.). Interdisciplinaridade: para além da filosofia do sujeito. Petrópolis: Vozes, 1995.

GADOTTI, Moacir. A organização do trabalho na escola: alguns pressupostos. São Paulo: Ática, 1993.

Interdisciplinaridade: atitude e método. São Paulo:

Instituto Paulo Freire. Disponível: <www.paulofreire.org > Acesso em: 26 dez. 2006.

GIBBONS, Michael et al. La nueva producción del conocimiento: la dinámica de la ciencia y la investigación en las sociedades contemporáneas. Barcelona: Pomares-Corredor, 1997.

GOLDMAN, Lucien. Dialética e cultura. Rio de Janeiro: Paz e Terra, 1979.
GUSDORF, G. La parole. Paris: Presses Universitaires de France, 1953. $124 \mathrm{p}$.

. Professores para que? Lisboa: Morais, 1967.

JAPIASSU, Hilton. Interdisciplinaridade e patologia do saber. Rio de Janeiro: Imago, 1976.

KAPP, K. W. Toward a science of man in society. A positive approach to the integration of social knowledge. Haia: Martinus Nijhoff, 1961.

KUHN, Thomas S. A estrutura das revoluções científicas. São Paulo: Perspectiva, 1989.

LEIS, Héctor Ricardo. Sobre o conceito de interdisciplinaridade. Cadernos de Pesquisa Interdisciplinar em Ciências Humanas, Florianópolis, n. 73, ago. 2005. Disponível em: <http://www.cfh. ufsc.br/ dich/TextoCaderno73.pdf>. Acesso em: 26 fev. 2006.

LUCK, Heloísa. Pedagogia da interdisciplinaridade. Fundamentos teórico-metodológicos. Petrópolis: Vozes, 2001.

MORAES, Maria Cândida. O paradigma educacional emergente. São Paulo: Papirus, 2002.

MORIN, Edgar. Educação e complexidade, os sete saberes e outros ensaios. São Paulo: Cortez, 2005.

PIAGET, Jean. Para onde vai a educação? Rio de Janeiro: José Olympio, 1973.

POMBO, Olga. Interdisciplinaridade: conceito, problema e perspectiva. In: A interdisciplinaridade: reflexão e experiência. Lisboa: Universidade de Lisboa, 1993. Disponível em: <http://www.educ.fc.ul.pt/docentes/opombo/mathesis/interdisciplinaridade.pdf>. Acesso em: 14 dez. 2003.

Interdisciplinaridade. Ambições e limites. Lisboa: Relógio d'Água, 2004.

SNOW, Charles P. The two cultures and a second look. An extended version of the two cultures and the scientific revolution. London: Cambridge University Press, 1959.

VYGOTSKY, Lev. Pensamiento y lenguaje. Buenos Aires: La Pléyade, 1986.

JUARES DA SILVA THIESEN, doutor em educação pelo Instituto Central de Ciências Pedagógicas (ICCP - Havana/Cuba), é professor no Centro de Educação da Universidade do Estado de Santa Catarina e no Departamento de Educação do Centro Universitário de São José. Últimas publicações: “A unidade docência: pesquisa como principio articulador na formação pedagógica e científica de educadores" (In: ENCONTRO NACIONAL DE DIDÁTICA E PRÁTICA DE ENSINO, 14., Porto Alegre, 2008. Anais... Porto Alegre: PUC-RS, 
2008). Olhares sobre educação: da realidade às perspectivas (Florianópolis: Insular, 2008); "Por um currículo de base histórico-cultural. 20 anos de discussão e implementação da Proposta Curricular de Santa Catarina" (In: SIMPÓSIO SOBRE ORGANIZAÇÃO E GESTÃO

ESCOLAR, 5., Aveiro, 2008. Anais... Aveiro/Portugal: Universidade de Aveiro, 2008). Pesquisa em andamento: "Elaboração de uma sistemática metodológica para a construção de cenários prospectivos na área da educação pública", no Programa de Pós-Graduação em Engenharia e Gestão do Conhecimento da Universidade Federal de Santa Catarina. E-mail: juaresthiesen@gmail.com

Recebido em agosto de 2007 Aprovado em julho de 2008 
portuguesa, especialmente na capitania de Minas Gerais, a presença das ordens religiosas foi proibida no início do século XVIII, e a assistência associada à instrução limitou-se à sua dimensão leiga ou esteve a cargo do Estado. Somente no final dos Setecentos é que surgiram instituições para a instrução dos pobres. Palavras-chave: Minas Gerais; história da educação; instrução elementar; assistência; escola

\section{Instruction and assistance in the} captaincy of Minas Gerais: from the actions of the chambers to schools for poor children (1750-1814) In this article we discuss the relations between the civilizing function of instruction and its charitable role based on a study of the actions of the chambers and religious institutions in favour of education for poor children. In the Ancient Regime, education for the lowest strata of the population was associated with the diffusion of the Christian doctrine and vocational training as a means of control carried out by charitable institutions. The teaching of the first letters was aimed at facilitating the learning of doctrine without creating the possibility of social ascension by means of education. The solution of vocational education, the learning of trades which could serve as an occupation and sustenance, was emphasized. The Portuguese legislation defined the destination to be given to orphans and the education which was destined to them had to be compatible with their original social status. In Portuguese America, especially in the captaincy of Minas Gerais, the presence of religious orders was prohibited at the beginning of the $18^{\text {th }}$ century and the assistance associated with instruction was limited to its lay dimension or was the responsibility of the State. Only at the end of the century did institutions for the instruction of the poor arise. Key words: Minas Gerais; history of education; elementary instruction, assistance; school

Instrucción y asistencia en la capitania de Minas Gerais: de las acciones de las cámaras a las escuelas para niños pobres (1750-1814)

En este artículo, se pretende discutir las relaciones entre la función civilizadora de la instrucción y de su papel de asistencia por el estudio de las acciones de las cámaras y de instituciones propias para la educación de niños pobres. En el Antiguo Régimen, la educación para las clases más bajas de la población se asociaba a la difusión de la doctrina cristiana y a la formación profesional como medios de control y, era realizada en instituciones de asistencia. La enseñanza de las primeras letras visaba facilitar el aprendizaje de la doctrina, sin crear posibilidades de ascensión social por la educación. Sobresalía la solución de la educación profesional, del aprendizaje de oficios que pudieran servir de ocupación y de sustento. La legislación portuguesa definía los destinos que serían dados a los huérfanos y, la educación que les sería destinada devería ser compatible con su nivel social de origen. En la América portuguesa, especialmente en la capitanía de Minas Gerais, la presencia de las órdenes religiosas fue prohibida en el inicio del siglo XVIII y, la asistencia asociada a la instrucción se limitó a su dimensión lega o estuvo a cargo del Estado. Solamente al final de los Setecientos es que surgieron instituciones para la instrucción de los pobres.

Palabras clave: Minas Gerais; historia de la educación; instrucción elemental; asistencia; escuela

Juares da Silva Thiesen

A interdisciplinaridade como um movimento articulador no processo ensino-aprendizagem

Discute a interdisciplinaridade como um movimento contemporâneo presente nas dimensões da epistemologia e da pedagogia, que vem marcando o rompimento com uma visão cartesiana e mecanicista de mundo e de educação e, ao mesmo tempo, assumindo uma concepção mais integradora, dialética e totalizadora na construção do conhecimento e da prática pedagógica. Inicialmente, faz-se uma breve apresentação da origem histórica desse movimento, discutem-se aspectos de sua conceituação e suas implicações no campo das diferentes ciências contemporâneas para então apresentar a interdisciplinaridade como um importante fenômeno de articulação do processo de ensino e aprendizagem. A argumentação apresentada no texto busca destacar que o movimento da interdisciplinaridade pode transformar profundamente a qualidade da educação escolar por intermédio de seus processos de ensino.

Palavras-chave: interdisciplinaridade; ciência; educação; processo de ensino e aprendizagem; conhecimento

\section{Interdisciplinarity as an articulating movement in the teaching-learning process}

The text discusses interdisciplinarity as a contemporary movement, present in epistemological and pedagogical dimensions. This movement is marking a break with the Cartesian and mechanist vision of the world and education and, at the same time, assuming a more integrated, dialectic and totalizing conception in the construction of knowledge and in pedagogic practice. To begin with, I make a brief presentation of the historical origin of the movement and discuss aspects of its conceptualization and its implications in the field of different contemporary sciences before presenting interdisciplinarity as an important phenomenon of the articulation of the teaching-learning process. The argument presented in the text seeks to 
emphasize that the interdisciplinarity movement can profoundly transform the quality of school education by means of its teaching processes.

Key words: interdisciplinarity; science; education; teaching-learning process; knowledge

\section{La interdisciplinariedad como un movimiento articulador en el proceso de enseñanza y aprendizaje}

Discute la interdisciplinariedad como un movimiento contemporáneo presente en las dimensiones de la epistemología y de la pedagogía, que viene marcando el rompimiento con una visión cartesiana y mecanicista de mundo y de educación y, al mismo tiempo asumiendo una concepción más integradora, dialéctica y totalizadora en la construcción del conocimiento y de la práctica pedagógica. Inicialmente, se hace una breve presentación del origen histórico de ese movimiento, se discuten aspectos de su conceptuación y sus implicaciones en el campo de las diferentes ciencias contemporáneas para entonces presentar la interdisciplinariedad como un importante fenómeno de articulación del proceso de enseñanza y aprendizaje. El argumento presentado en el texto busca destacar que el movimiento de la interdisciplinariedad puede transformar profundamente la calidad de la educación escolar por intermedio de sus procesos de enseñanza.

Palabras clave: interdisciplinariedad; ciencia; educación; proceso de enseñanza y aprendizaje; conocimiento

Fernanda Wanderer e Gelsa Knijnik

Discursos produzidos por colonos do sul do país sobre a matemática e a escola de seu tempo

$\mathrm{O}$ artigo apresenta resultados parciais de uma investigação que teve como propósito analisar discursos sobre a escola e a matemática escolar produzidos por um grupo de colonos, descendentes de alemães e evangélico-luteranos que freqüentavam uma escola rural do município de Estrela (RS), quando da efetivação dos decretos que instituíram a Campanha de Nacionalização - uma das medidas do Estado Novo (19371945), implementado no Brasil por Getúlio Vargas. A sustentação teórica do estudo encontra-se no campo da etnomatemática - constituído mediante os entrecruzamentos das teorizações pós-estruturalistas, em especial o pensamento de Michel Foucault, e das idéias formuladas por Ludwig Wittgenstein em sua obra Investigações filosóficas. O material de pesquisa examinado no artigo consiste em narrativas produzidas por sete colonos que estudaram naquela escola no período enfocado e em um texto elaborado por um dos participantes da pesquisa. $\mathrm{O}$ exercício analítico realizado mostrou que: a matemática escolar praticada naquela instituição foi sendo constituída como um conjunto de jogos de linguagem marcados pela escrita e pelo formalismo; as matemáticas geradas nas atividades cotidianas dos participantes do estudo podem ser significadas como conformando jogos de linguagem regidos por outra gramática, que utilizava regras como a oralidade, a decomposição, a estimativa e o arredondamento, constituindo critérios de racionalidade diferentes daqueles presentes nos jogos que engendravam a matemática escolar. Palavras-chave: matemática escolar; etnomatemática; teorizações pósestruturalistas

\section{Discourses produced by settlers} in the south of Brazil on the mathematics and school of their time The paper presents the partial results of research carried out with the aim of analysing the discourses on school and school mathematics of a group of German-descendant EvangelicalLutheran settlers who attended a rural school in Estrela (State of Rio Grande do Sul), at the time of the Nationalization Campaign - one of the actions taken by Getúlio Vargas during the Estado Novo (1937-1945) in Brazil. The theoretical framework of the study is the field of ethno-mathematics - shaped by poststructuralist theorizing, especially Michel Foucault's thinking, and the ideas of Ludwig Wittgenstein in his work Philosophical investigations. The data examined in the article consist of narratives produced by seven settlers who studied at the school during that period and a text written by one of the research participants. The analytical exercise carried out showed that: a) the school mathematics developed in that institution was instituted as a set of language games marked by writing and formalism; $b$ ) the mathematics generated by the settlers' everyday activities shaped language games constituted by another grammar, marked by rules such as orality, decomposition, estimations and rounding, which constitute rationality criteria that are different from those of the school mathematics language games.

Key words: school mathematics; ethno-mathematics; post-structuralist theorizing

Discursos producidos por colonos del sur del país sobre la matemática y la escuela de su tiempo

El artículo presenta resultados parciales de una investigación que tuvo como finalidad analizar discursos sobre la escuela y la matemática escolar producidos por un grupo de colonos, descendientes de alemanes y evangelistas luteranos que frecuentaban una escuela rural del municipio de Estrela (RS), cuando la efectividad de los decretos que establecieron la Campaña de Nacionalización - una de las medidas del Estado Nuevo (1937-1945), 